\title{
Board 106: Quantitative and Qualitative Assessment of Large-Scale Inter- ventions in a First-Year Experience Program
}

\section{Dr. Gustavo B Menezes, California State University, Los Angeles}

Menezes is a Professor of Civil Engineering at Cal State LA. His specialization is in Environmental and Water Resources Engineering. Since becoming part of the faculty in 2009, Menezes has also focused on improving student success and has led a number of engineering education projects. He is currently the Director of the First-Year Experience program at ECST (FYrE@ECST) and coordinates engineering education activities at the college of engineering, computer science and technology (ECST). He has also developed an open access, web-based audience response system (educatools.com).

\section{Dr. Emily L. Allen, California State University, Los Angeles}

Emily L. Allen, Ph.D., is Dean of the College of Engineering, Computer Science, and Technology at California State University, Los Angeles. She earned her BS in metallurgy and materials science from Columbia University, and her MS and $\mathrm{PhD}$ in materials science and engineering from Stanford University. She previously served as faculty, chair and Associate Dean at San Jose State University's College of Engineering. Dr. Allen believes in a collaborative, student-centered approach to research, education and academic administration and leadership. She currently serves on the ASEE Engineering Deans Council Executive Board, the ABET Academic Affairs Council, and chairs the ABET Task Force on Diversity and Inclusion.

\section{Dr. Gisele Ragusa, University of Southern California}

Gisele Ragusa is a Professor of Engineering Education at the University of Southern California. She conducts research on college transitions and retention of underrepresented students in engineering and also research about engineering global preparedness and engineering innovation. She also has research expertise in STEM K-12 and in STEM assessment. She chairs USC's STEM Consortium.

\section{Eva Schiorring, Canada College}

Eva Schiorring has almost two decades of experience in research and evaluation and special knowledge about STEM education in community colleges and four-year institutions. She presently serves as the external evaluator for four NSF-funded projects. These include evaluation of a first year experience in a majority-minority engineering college and an initiative to increase diversity in a predominantly white elite engineering college through collaboration with local community colleges. Ms. Schiorring is also evaluating an ATE project to bolster recruitment and preparation of diverse STEM teachers. Past projects include evaluation of an NSF-funded project to improve advising for engineering students at a major state university in California. Ms. Schiorring is the author and co-author of numerous papers and served as project lead on a major study of transfer in engineering. Ms. Schiorring holds a Master's Degree in Public Policy from Harvard University. She is a graduate of NSF's I-Corps program for educators.

\section{Dr. Paul S Nerenberg}

Dr. Paul S. Nerenberg is currently an Assistant Professor of Physics and Biology at California State University, Los Angeles. He received his $\mathrm{PhD}$ in Physics from MIT and has a strong interest in improving the quality of introductory physics education, particularly for students who enter college with little or no previous physics coursework. 


\section{Quantitative and Qualitative Assessment of Large-Scale Interventions in a First-Year Experience Program}

\section{$\underline{\text { Abstract }}$}

In this Work-in-Progress paper, we report on the challenges and successes of a large-scale FirstYear Engineering and Computer Science Program at an urban comprehensive university, using quantitative and qualitative assessment results. Large-scale intervention programs are especially relevant to comprehensive minority serving institutions (MSIs) that serve a high percentage of first-generation college students who often face academic and socioeconomic barriers. Our program was piloted in 2015 with 30 engineering students, currently enrolls 60 engineering and computer science students, and is expected to grow to over 200 students by Fall 2020. The firstyear program interventions include: (i) block schedules for each cohort in the first year; (ii) redesigned project-based introduction to engineering and introduction to computer science courses; (iii) an introduction to mechanics course, which provides students with the foundation needed to succeed in the traditional physics sequence; and (iv) peer-led supplemental instruction (SI) workshops for Calculus, Physics and Chemistry. A faculty mentorship program was implemented to provide additional support to students, but was phased out after the first year. Challenges encountered in the process of expanding the program include administrative, such as scheduling and training faculty and SI leaders; barriers to improvement of math and science instruction; and more holistic concerns such as creating a sense of community and identity for the program. Quantitative data on academic performance includes metrics such as STEM GPA and persistence, along with the Force Concept Inventory (FCI) for physics. Qualitative assessments of the program have used student and instructor surveys, focus groups, and individual interviews to measure relationships among factors associated with college student support and to extract student perspectives on what works best for them. Four years of data tell a mixed story, in which the qualitative effect of the interventions on student confidence and identity is strong, while academic performance is not yet significantly different than that of comparison groups. One of the most significant results of the program is the development of a FYrE Professional Learning Community which includes faculty (both tenure-track and adjunct), department chairs, staff, and administrators from across the campus.

\section{Introduction}

For decades, engineering education researchers and practitioners have developed, implemented and assessed a number of interventions to provide support for at-risk students (such as firstgeneration college students) to help them succeed in college STEM majors, particularly in their first year. These interventions typically target a relatively small number of students and can be managed by a small number of faculty and staff.

In this Work-in-Progress paper, we report on the challenges and successes of a large-scale FirstYear Engineering and Computer Science Program at California State University, Los Angeles (Cal State LA), an urban comprehensive university, through quantitative and qualitative assessment results. Large-scale intervention programs are especially relevant to comprehensive minority serving institutions (MSIs) that serve a high percentage of first-generation college 
students who often face academic and socioeconomic barriers. Our program was piloted in 2015 with 30 engineering students, currently enrolls 60 engineering and computer science students, and is expected to grow to over 200 students by Fall 2020. The first-year program interventions include: (i) block schedules for each cohort in the first year; (ii) redesigned project-based introduction to engineering and introduction to computer science courses; (iii) an introduction to mechanics course, which provides students with the foundation needed to succeed in the traditional physics sequence; and (iv) peer-led supplemental instruction (SI) workshops for Calculus, Physics and Chemistry. Challenges encountered in the process of expanding the program include administrative, such as scheduling and training faculty and SI leaders; barriers to improvement of math and science instruction; and more holistic concerns such as creating a sense of community and identity for the program. Quantitative data on academic performance include metrics such as STEM GPA and persistence in major, along with the Force Concept Inventory (FCI) for physics. Qualitative assessments of the program have used student and instructor surveys, focus groups, and individual interviews to measure relationships among factors associated with college student support and to extract student perspectives on what works best for them. Four years of data tell a mixed story, in which the qualitative effect of the interventions on student confidence and identity is strong, while academic performance is not significantly different than that of comparison groups. One of the most significant results of the program thus far is the development of a FYrE Professional Learning Community which includes faculty (both tenure-track and adjunct), department chairs, staff, and administrators from across the campus.

This paper will focus on initial outcomes of the program, , how we measure its effectiveness, the challenges of scaling the program to an entire College, as well as on the cultural and attitudinal changes which have been required in the students, faculty and staff of the College in order to fully integrate this program. We will also highlight how our students' strengths have been utilized to build a community that sustains itself and outpaces the student-deficit model that often pervades engineering institutions with large numbers of students who have been historically underrepresented in STEM.

\section{$\underline{\text { Institutional Context }}$}

Cal State LA is an HSI, one of 23-campuses of the California State University system, which prides itself on being an access institution, and as such admits students mainly from a specific urban geographical sub-region. The undergraduate student body of the College of Engineering, Computer Science, and Technology closely matches that of the university as a whole, and comprises 66\% Latinx, 15\% Asian-American, 8\% white, and $8 \%$ international, with around 70\% of the total identifying as first-generation to college, low income (maximum Pell-grant eligible), and from local public schools serving the lowest SES families in a large metropolitan region. The undergraduate international population ( $8 \%$ ) is mainly California resident, undocumented students. The population of women in the College is $15 \%$, which is below the national average for engineering programs. Admission to the university is based on an Eligibility Index which combines high school GPA and SAT or ACT scores. Admission requirements for first-time freshmen in the College of Engineering, Computer Science, and Technology are the same as those of the University; we serve all comers. 
Over the last five years, the campus underwent several major changes under a new president, including rapid enrollment growth; the College tripled in five years. In Fall 2016, the institution converted from the quarter system to the semester system, with a concomitant overhaul of the entire curriculum, complicating some comparisons of student cohort performance. In Fall 2017 the University implemented the $\mathrm{EAB}^{1}$ student success data platform, which has enabled targeted intervention advising and improved our ability to track individual students. In Fall 2018, the university eliminated the teaching of remedial math, and substituted a summer accelerated math course to students considered unprepared for college math based on their eligibility index. Also, beginning in Fall 2018, freshman Engineering (CE, ME, \& EE) and CS students are admitted to the pre-Major until they have completed a set of lower division courses (the "major-specific criteria" or MSC) with C or better. If the MSC are not completed within 60 units, the student will not be transitioned to the major and must find another degree objective. Currently these courses for all engineering (Engr)/ Computer science (CS) majors are Calculus (Calc) I \& II, Phys I (Mechanics), and Chemistry for Engineers or Programming (for CS majors).

The College currently (Fall 2018) has over 3200 undergraduates, and 65 tenured or tenure-track faculty. At least half of the College classes are taught by contract faculty (lecturers, or adjunct faculty). Virtually all first and second-year classes in math and science, which form the fundamental basis for our Engr and CS degrees, are taught by lecturers in the College of Natural and Social Sciences. Thus our ability to build a community among first-year math and science instructors is somewhat hampered by the fact that these instructors are hired and supervised by other departments.

\section{Programs preceding the FYrE Program}

The College initiated a Minority Engineering Program (MEP) in the 1990s, but as the overall enrollment increased, and specifically the proportion of low income and first generation students, it became clear almost a decade ago that to meet the needs of our students, the entire college needed to operate as an MEP program. With limited resources, the scale of the need, and our ability to offer support and services to virtually all students, is a challenge, and quite a different scenario than an MEP program for a small group of under-represented students within a wellprepared majority population. Interventions to improve success for under-represented and firstgeneration students in engineering are well-known, but scaling them to an entire College is not a simple matter.

More than two decades ago we began utilizing Academic Excellence Workshops (AEW) modeled on Uri Treisman's collaborative learning model ${ }^{2}$ to improve math and science outcomes. Over a decade ago a summer bridge program (STEP) was added for pre-matriculation freshmen, in the form of a 7-week math bootcamp. STEP was organized around faculty instruction and peer-led workshops, and concluded with an exit exam protocol to place students into pre-calculus or calculus for the freshman Fall term.

\footnotetext{
${ }^{1}$ EAB's Student Success Collaborative dashboard provides data and intelligence to assist faculty, staff and administrators in tracking, alerting, and gathering knowledge about student success. https://www.eab.com/ 2 Treisman, Uri. (1983). Improving the Performance of Minority Students in College-Level Mathematics. Innovation Abstracts. 5.
} 
Both the STEP and AEW interventions have had successful short-range outcomes in terms of improved placement into calculus courses, and successful long-range outcomes in terms of building strong student cohorts. However six-year graduation rates have remained stubbornly in the $30-40 \%$ range (for cohorts starting out in the College and obtaining degrees from any major at the institution; rates for starting and earning degrees in College majors are considerably lower). The STEP program was successful at getting students to calculus, but it is not clear if it was successful preparing students to succeed in calculus. It was also not clear whether the difficulty lay in the students or in the teaching methods.

We determined that the biggest barrier to 6-year graduation lay in the prevalence of students failing their first and/or second calculus classes, along with first physics class, and that the only way to improve our graduation rates would be to either drastically change our admissions requirements, or revolutionize the learning and accomplishments of our students during their first year. Since the former was not an option, we focused on the latter. In 2014 the College began an experiment entitled First-Year Experience (FYrE), supported by a grant from the Helmsley Foundation $^{3}$. Most recently, we were awarded an NSF IUSE grant to scale the program and continue measuring its effects on students ${ }^{4}$.

The FYrE program was initiated at a time when we sought to change the culture and operations of the College from student-centered to student-success centered, and to align students, faculty and staff on new approaches to student success. Instead of asking whether the students were college-ready, we began to ask whether the College was student-ready.

\section{$\underline{\text { The FYrE Program }}$}

The components of the FYrE program ${ }^{5}$ are listed in Table 1, and a discussion of the evolution of the program and the rationale for the changes in FYrE over time is provided below.

For the Fall15 FYrE pilot, a cohort of 30 students was selected randomly (using propensitymatching to college demographics) out of STEP students who had placed into Calc I for Fall 2015. The pilot group was cohorted their first quarter into Calculus, a Supplementary Instruction workshop $^{6}$, and a pilot section of Introduction to Engineering and Technology ${ }^{7}$, a new freshman course intended to launch full-scale in Fall 2016. During winter and spring quarters they were also cohorted in Calc II and III, and Physics I.

\footnotetext{
${ }^{3}$ STEM Collaborative grant awarded by the Leona M. and Harry B. Helmsley Charitable Trust.

4 "IUSE:The First-Year Experience at ECST," DUE-\#1727054.

${ }^{5}$ Menezes, G. B., \& Won, D., \& Tufenkjian, M., \& Allen, E. L., \& Schiorring, E. (2017, June), An Integrated First-Year Experience at ECST (FYrE@ECST) Paper presented at 2017 ASEE Annual Conference \& Exposition, Columbus, Ohio.

${ }^{6}$ Kornblum, S. L., \& Avery El, Z. K., \& Menezes, G. B., \& Won, D., \& Allen, E. L. (2017, August), Enhancing Engineering First-Year Experience (FYrE) through Supplemental Instruction Paper presented at 2017 FYEE Conference, Daytona Beach, Florida.

${ }^{7}$ M. Tufenkjian, M. Eshraghi, A. Jamehbozorg, M. Castillo, E. Allen and E. B. Schiorring, "Development of an oceanthemed introduction to engineering \& technology course for freshmen students," OCEANS 2017 - Aberdeen, Aberdeen, 2017, pp. 1-4.
} 
Table 1. FYrE Program Components

\begin{tabular}{|c|c|c|c|c|}
\hline Year & FYrE15 & FYrE16 & FYrE17 & FYrE18 \\
\hline Cohort Size & 30 & 67 & 57 & 57 \\
\hline Majors & $\mathrm{ME}, \mathrm{EE}, \mathrm{CE}$ & $\mathrm{ME}, \mathrm{EE}, \mathrm{CE}$ & $\mathrm{ME}, \mathrm{EE}, \mathrm{CE}, \mathrm{CS}$ & ME, EE, CE, CS \\
\hline $\begin{array}{l}\text { Cohort course } \\
\text { sections }\end{array}$ & $\begin{array}{l}\text { Calc I \& II, } \\
\text { Phys I, } \\
\text { SI workshops }\end{array}$ & $\begin{array}{l}\text { Calc I \& II, } \\
\text { Phys I, } \\
\text { Engr1500; } \\
\text { SI workshops }\end{array}$ & $\begin{array}{l}\text { Calc I \& II, Phys I, } \\
\text { Engr 1500; } \\
\text { SI workshops }\end{array}$ & $\begin{array}{l}\text { Calc I \& II } \\
\text { Intro to Mechanics } \\
\text { Phys I } \\
\text { Engr1500/CS1010 } \\
\text { SI workshops }\end{array}$ \\
\hline New components & $\begin{array}{l}\text { Engr1500 } \\
\text { (pilot) }\end{array}$ & & $\begin{array}{l}\text { CS1010 } \\
\text { Intro to Mechanics } \\
\text { (pilot) }\end{array}$ & $\begin{array}{l}\text { Chemistry (for Engr } \\
\text { majors only) }\end{array}$ \\
\hline $\begin{array}{l}\text { Calculus } \\
\text { Placement } \\
\text { Method }\end{array}$ & $\begin{array}{l}\text { STEP Exit } \\
\text { Exam }\end{array}$ & $\begin{array}{l}\text { STEP Exit } \\
\text { Exam }\end{array}$ & STEP Exit Exam & STEP ALEKS PPL \\
\hline Advising tools & $\begin{array}{l}\text { Advising with } \\
\text { Golden Eagle } \\
\text { Flight Plan }\end{array}$ & $\begin{array}{l}\text { Advising with } \\
\text { Golden Eagle } \\
\text { Flight Plan }\end{array}$ & $\begin{array}{l}\text { Dedicated staff } \\
\text { advisor; } \\
\text { Faculty Mentors }\end{array}$ & Dedicated staff advisor \\
\hline
\end{tabular}

The FYrE16 cohort had 67 students, on the new semester system, chosen randomly from eligible and interested STEP students. We had a change in management of the FYrE grant and some discord between faculty and staff around issues of FYrE programming, scheduling and support. A new FYrE Director was appointed and the university's Provost provided additional support for this position, which supplemented the grant funding.

The FYrE17 cohort of 57 students also included Computer Science majors and a new hands-on introductory CS course. Due to the difficulty students were having in their Physics I (Mechanics) class, even with SI workshops, we added a "pre-physics" class, Introduction to Mechanics9, intended to strengthen students' fundamental understanding of force and energy concepts and to build physical understanding of mechanics concepts.

The FYrE18 cohort was selected differently than the preceding cohorts because of a change in the STEP program, which in turn changed due to the university's legislatively required elimination of remedial math. This result of the elimination was that fewer students were involved in STEP since many were required to attend a summer accelerated math program (itself built on some of our STEP successes). Another change was that ALEKS PPL ${ }^{10}$ was used throughout STEP both as a source of online math practice and as a calculus placement tool. Students had five opportunities to test into Calculus 1 during the summer STEP program, by achieving a score of 76 on the ALEKS calculus prep module. ALEKS is an adaptive learning

\footnotetext{
${ }^{8}$ Sun C, Won D, Allen E. L, Gadhia H. Golden eagle flight plan online: A web-based advisement tool to facilitate developmental advising. American Society of Engineering Education Annual Meeting, New Orleans, LA. 2016. ${ }^{9}$ N. Li, G.B. Menezes, P. Nerenberg, E. Allen, "First-Year Experience (FYrE@ECST): Intro to Physics Course (WIP)”, 2018 The Collaborative Network for Engineering and Computing Diversity (CoNECD), Crystal City, VA, 2018. ${ }^{10}$ ALEKS. (2019). Overview of ALEKS. Retrieved from http://www.aleks.com/about_aleks/overview
} 
program and thus not all students were tested on the same questions to be considered calculus ready.

For FYrE 2018 we also added the freshman chemistry class to the Fall schedule, because changes in engineering curricula made completing chemistry in the first year an important step on the critical path towards a four-year degree.

The research intent of this program is to study the short and long term impacts of a scaled first year experience program on participating students while enrolled in the college of engineering. Accordingly, such impacts include the various factors (programmatic, socio-demographic, and affective) that influence students persistence in engineering and computer science majors and their academic performance. For this paper we turn to preliminary results related to the development of the FYrE program in addition to first year results from 2017-2018, as this is a work in progress paper.

\section{$\underline{\text { FYrE First-Year Performance Results }}$}

Over the four years of the program, the research team has investigated latitudinal and longitudinal data to assess FYrE student performance and program effectiveness, and to compare it to cohorts not enrolled in the FYrE program but those who have enrolled in Calculus their freshman year in college (Non-FYrE Cohorts or comparison groups).

\section{Academic Performance by STEM GPA}

To evaluate first-year performance rates of FYrE cohorts, we compared first-year STEM GPA (GPA for only math, physics and engineering courses taken the first year). The FYRE15 cohort performance was compared to a propensity-matched control group who also completed STEP and started in Calculus in the Fall. The FYRE16 and FYRE17 cohort performance was compared to all other Calc-starting freshmen, which may have included students who did not attend STEP and advanced to Calculus using high school AP exam scores. To compare performance further, students have been categorized into one of three groups:

1. The category of Completers refers to members of the cohort who complete Calc I, Calc II, and Physics I with a $\mathrm{C}$ or better in their first year.

2. Persisters refers to students who remain enrolled in Engr or CS majors after the first year, but did not complete the three courses with $\mathrm{C}$ or better, either because they delayed enrollment in courses, or because they had to repeat a course. It should be noted that institutional policies allow students a limited number of course repeats with "grade replacement," meaning that the grade in a second attempt of a course will replace the earlier grade, with no GPA degradation. Thus generally first-year course repeaters may achieve higher GPAs than first-year completers, but have slower progress to degree. Note that Persisters and Completers taken together represent the students retained in an engineering or CS major at the end of the first year.

3. Non-Persisters include students who have changed major (out of Engr or CS), have stopped out, left the university or been disqualified, or for some other reason were not enrolled in an Engr or CS during Spring of the first year or Fall of the second year. For non-Persisters, the STEM GPA used may be from the Fall semester rather than 
cumulative after two semesters. Note that many students switch to other majors in the university and are counted as Non-persisters in this data, but may be well on their way to a successful degree in another field. It should also be noted that many engineering students change major during the first year to Industrial Technology, which is within our College, and make better progress to degree thereafter. Similarly, some CS students switch to Computer Information Systems (in the Business school). Onene of the goals of FYrE is to help students into the right major early in their college career.

Figure 1, Figure 2, and Figure 3 each illustrate the first year median STEM GPAs (LH axis) for each FYrE cohort compared to its Non-FYrE cohort. The right-hand axis shows the distribution among the three categories (Completer, Persister, or Non-Persister) for each cohort.

For all cohorts, after two semesters Completers have higher median GPAs than Persisters, and Non-persisters achieved lower GPAs. The academic performance results do not indicate strong performance differences between students in the FYRE cohorts and other students. In some years, the Non-FYrE students had higher median GPAs for both Completers and Persisters. The percentage retained in major (Completers + Persisters) was similar for both FYrE and Non-FYrE cohorts, though there was variation overall year to year, as shown in Table 2 . In interpreting the GPA results, one reason that Non-FYrE persisters may have higher or equivalent GPAs, is that as mentioned above, repeating a class may not degrade a student's GPA because they may be awarded "grade forgiveness" for a certain number of units. Other data also shows that FYrE Persisters take more STEM courses than Non-FYrE persisters, which may potentially contribute to a lower GPA.

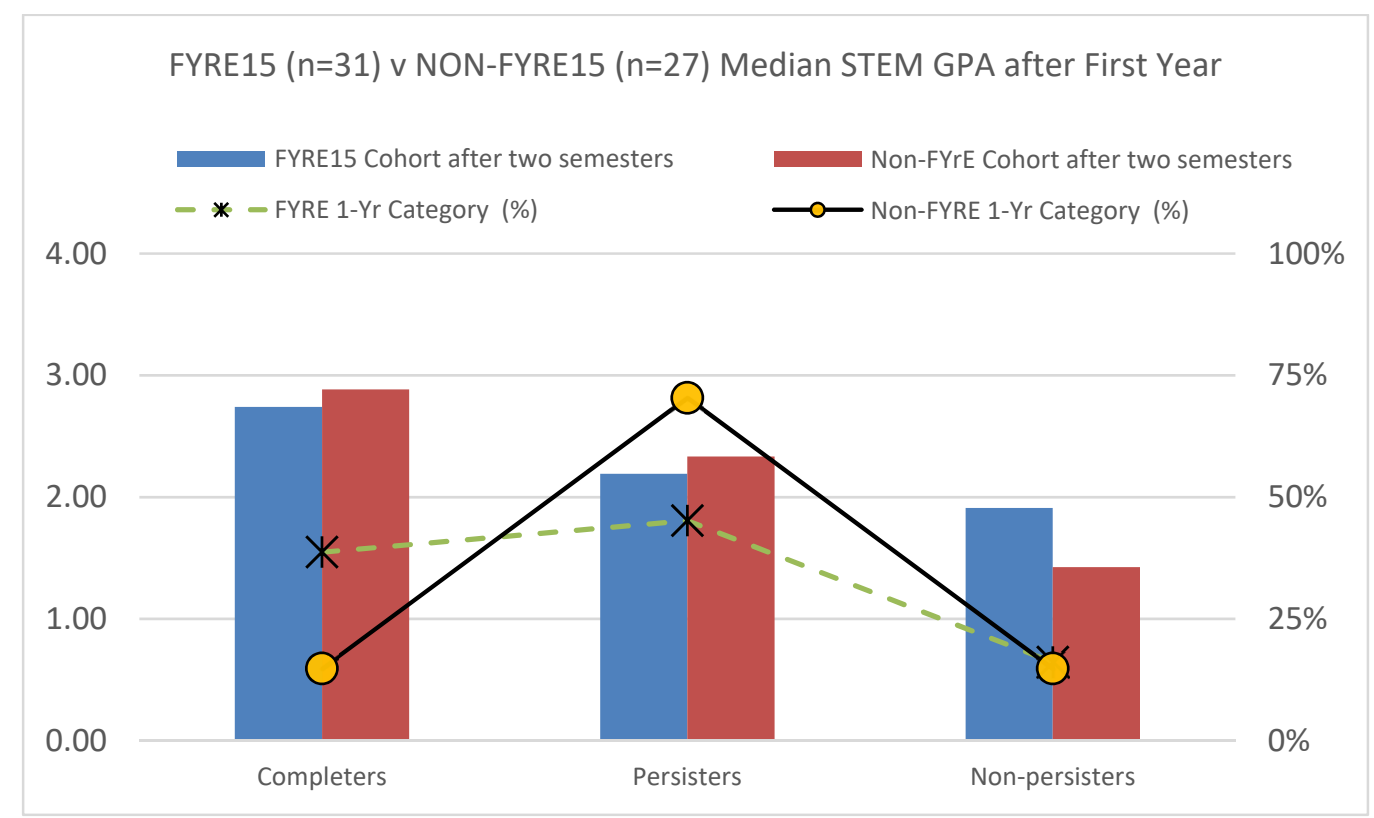

Figure 1. First-year performance (STEM GPA) and outcome data from Fall $2015 \mathrm{FYrE}$ and Non-FYrE cohort. 


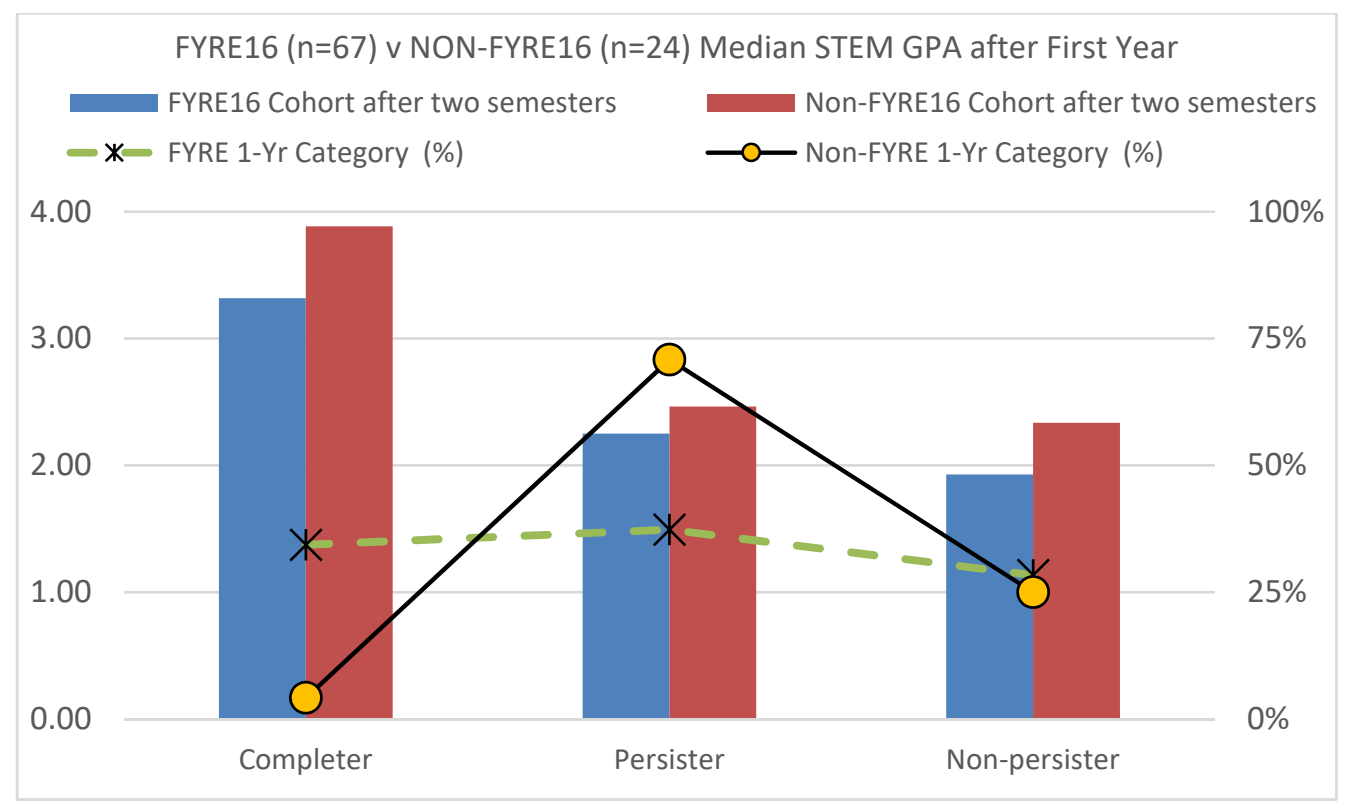

Figure 2. First-year performance (STEM GPA) and outcome data from Fall 2016 FYrE and Non-FYrE cohorts.

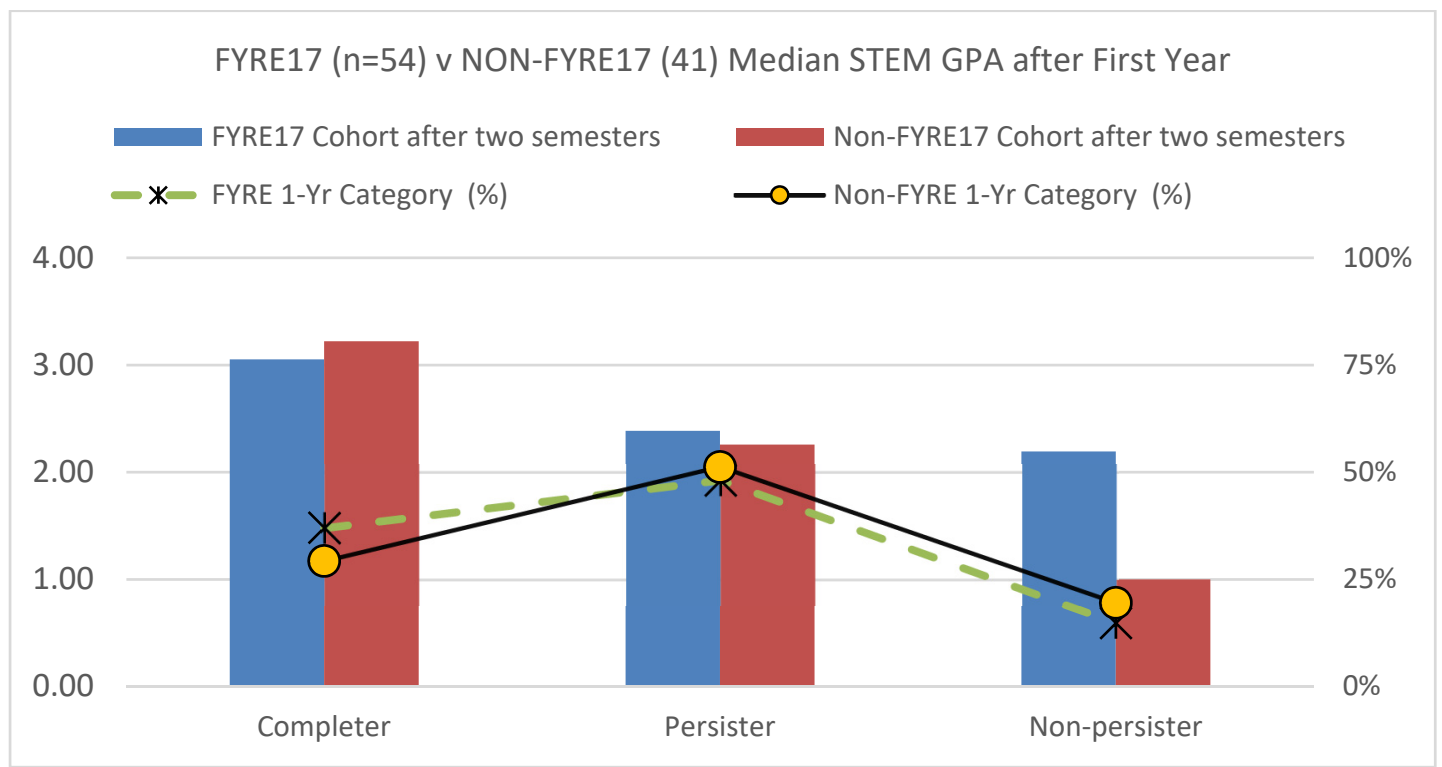

Figure 3. First-year performance (STEM GPA) and outcome data from Fall 2017 FYrE and Non-FyrE cohorts.

Table 2. Retention rate (in Engr or CS) after one year for both FYrE and Non-FYrE cohorts

\begin{tabular}{|l|l|l|l|}
\hline Category after two semesters & F15 & F16 & F17 \\
\hline Retained FYRE & $84 \%$ & $72 \%$ & $85 \%$ \\
\hline Retained Non-FYrE & $85 \%$ & $75 \%$ & $80 \%$ \\
\hline
\end{tabular}


In all three years, the percentage of Completers is consistently higher for the FYrE cohorts. Also, although the GPA of FYrE groups seems lower, the number of non-FYrE completers is also very low, which can be an indication that only a few better prepared students were able to complete the two calculus and one physics class, while less prepared students in FYrE were able to complete the 3 courses because of the support provided by the FYrE program. It is also interesting to note that the percentage of Non-persisters is virtually the same for FYrE and nonFYrE students, which is an indication that there is a percentage of students that has either picked the wrong major or would not be able to complete college even when support is provided. As expected, in general Non-persisters have a lower GPA than other groups.

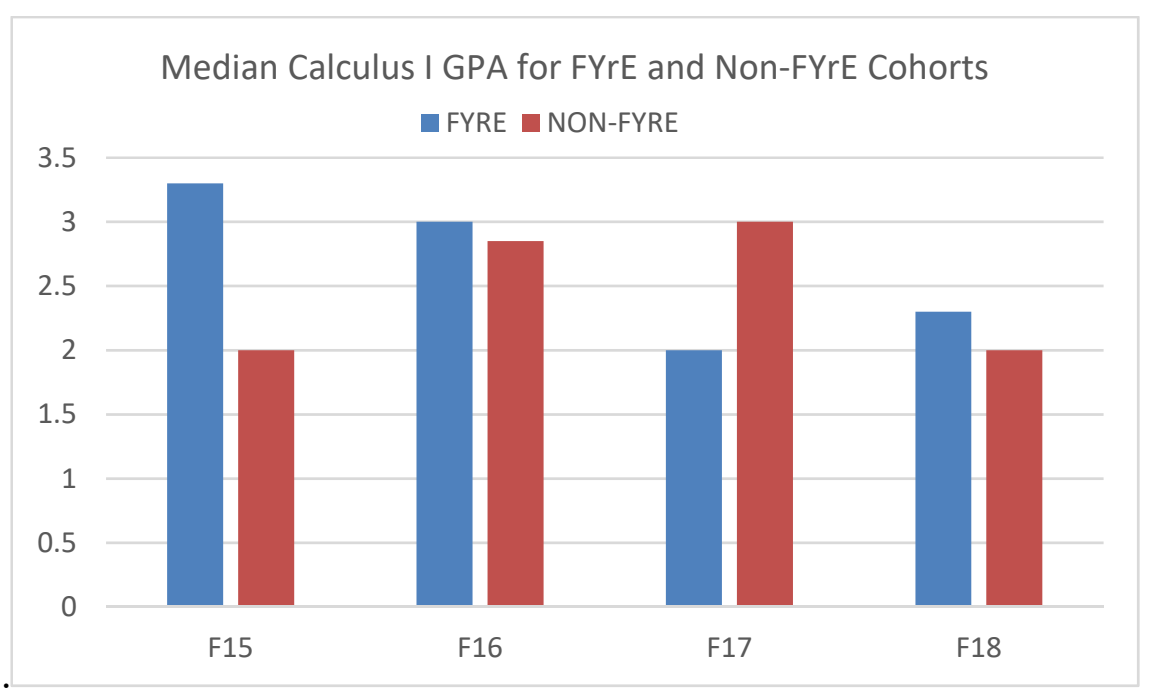

Figure 4. Median Calculus I GPA for FYrE and Non-FYrE freshman cohorts.

Due to reasons detailed above, the first-year GPA may not be an accurate metric to use in determining whether FYrE is making an improvement is student performance. Figure 4 shows only the first term Calculus median GPA for each cohort. Except for Fall 17, the FYrE cohorts had better performance in this course. However the extreme (almost one GPA point) difference in F17 led us to examine the pass/fail rate in all the calculus class sections that term, which has led to major concerns about inconsistent teaching and/or grading in the large numbers of calculus sections, which is certainly adding an uncontrolled variable to our analysis of the FYrE results.

Figure 5 shows Calculus I grades for all calculus sections taught at the University in (a) Fall 2017 and (b) Fall 2018 semesters. In this figure, FYrE1 refers to a section for FYrE students, while NF01 is a section with only Non-FYrE enrollees; the blue bars indicate grades of D or F, the so-called "DFW" rate. Figure 5(a) indicates that there is wide variability across sections, and that the FYrE1 section had the third highest DFW rate $(50 \%)$. After further investigation we learned that the assigned instructor for FYrE1 Fall 17 section had a long record of exceptionally low passing rates (compared to department average), making it clear that providing support to students would not be sufficient to impact academic performance. Accordingly, after that year, we began working with the Math Department Chair to identify faculty who were open to changing their teaching practices and receptive to the FYrE philosophy, given that the university needs to adapt to the needs of first generation students. Figure 5(b) shows that performance results improved in the Fall 2018 semester, with the FYrE sections having pass rates slightly above department average. 


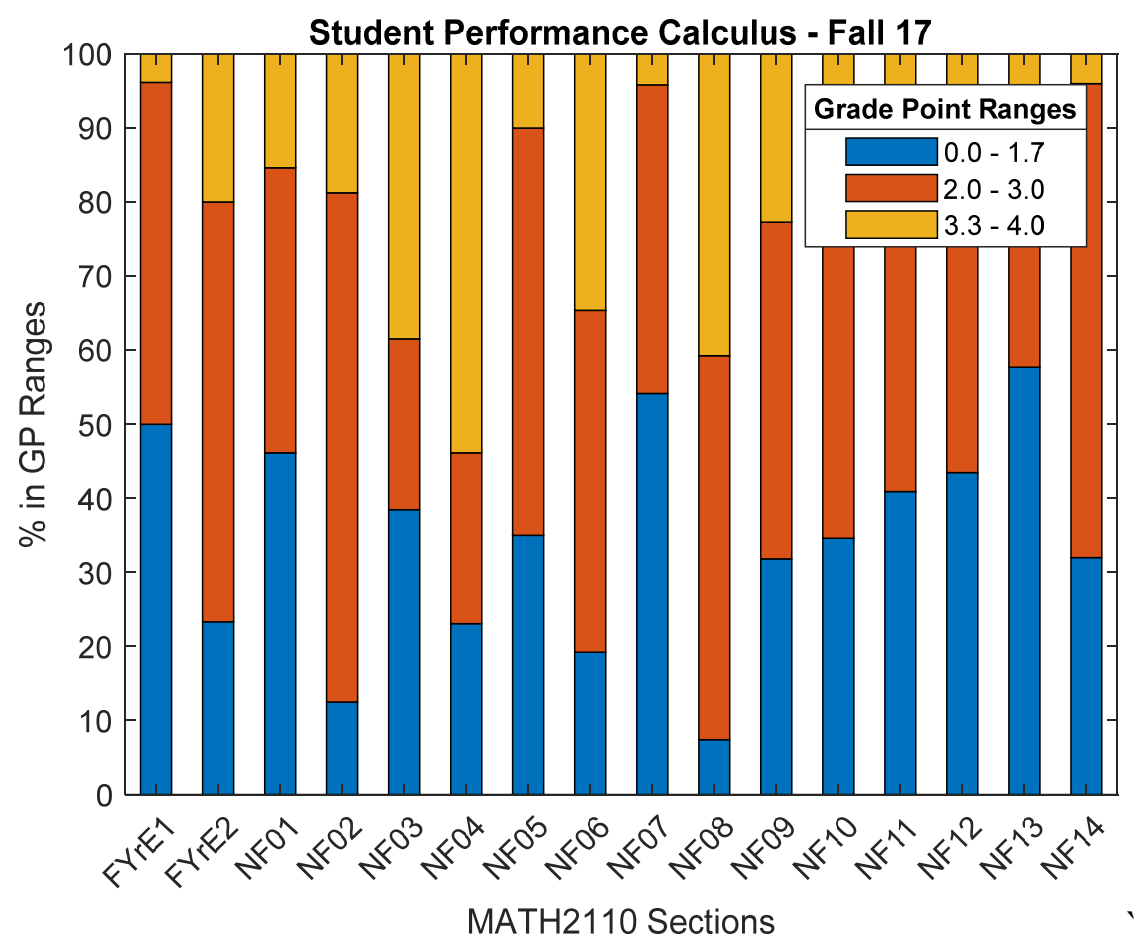

(a)

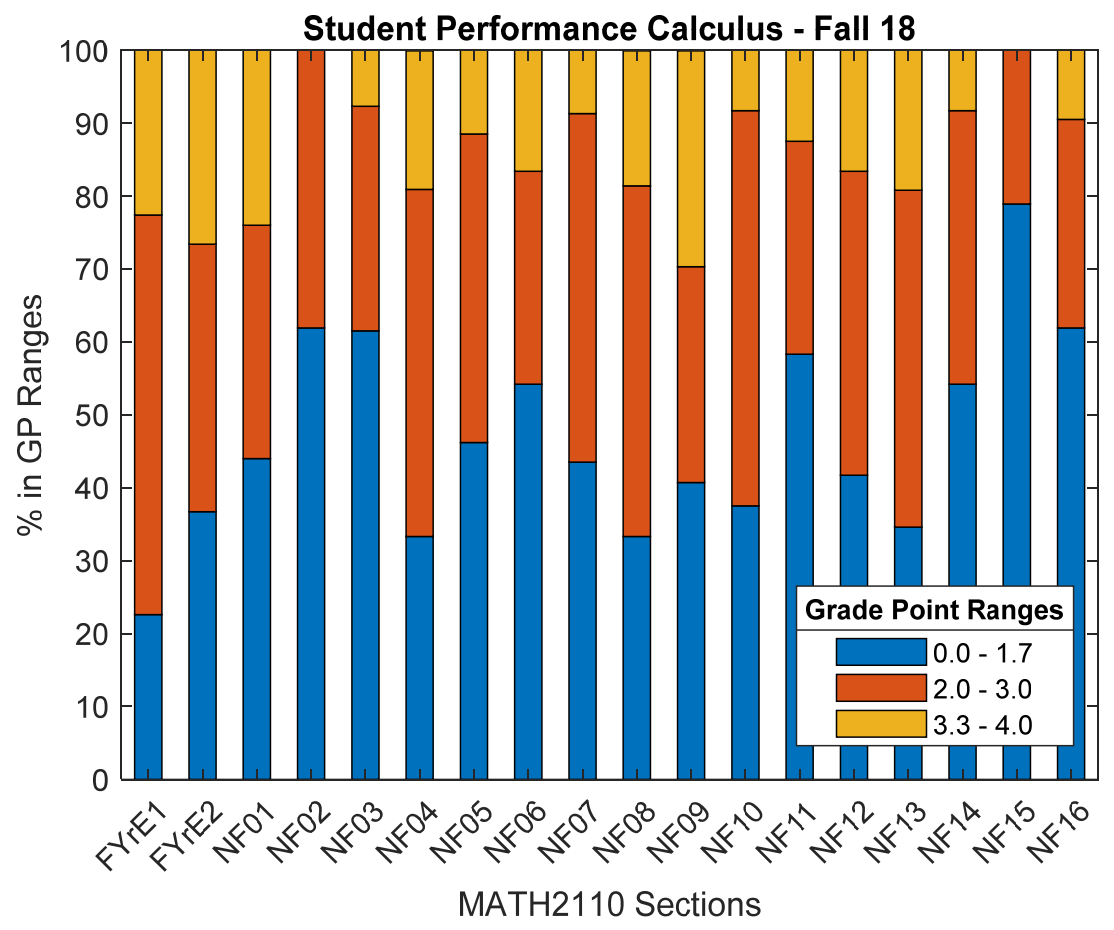

(b)

Figure 5. Student Performance in Calculus I (a) Fall 2017 and (b) Fall 2018. For example, FYrE1 is a section for FYrE students, while NF01 is a section with only Non-FYrE enrollees. 
In the case of Physics I (Mechanics) courses, sections are larger (and fewer), so variability is not as evident as in Calculus; nevertheless similar problems exist and GPA has been traditionally low for FYrE and non-FYrE sections. The physics section for Spring 2018 was a mixed section with both FYrE and Non-FYrE students; the percentage of DFWs for FYrE and Non-FYrE students was $42 \%$ and $72 \%$, respectively. The better performance of the FYrE group is attributed to the Intro to Mechanics course they had taken in the preceding semester, piloted in Fall 2017 as part of the FYrE program.

The improved grades of the FYrE cohort is consistent with results of the Force Concept Inventory (FCI ${ }^{11}$, a well-established measure of student understanding of fundamental force concepts typically taught in the standard first physics (mechanics) course.

Figure 6 shows the pretest (start of course) and posttest (end of course) FCI scores for FYrE and Non-FYrE (all non-FYrE STEM students) enrolled in physics in Spring 2018. As shown in the plot, the median FCI score of the FYrE group was $40 \%$ higher than non-FYrE students in the pretest (administered on the first day of classes) and 36\% higher on the posttest (administered in the last week of classes). It is important to consider that non-FYrE groups may include repeating students (those who have taken a course more than once). Another important finding is that the posttest average gain is small for both groups, and only a small portion of all the physics students achieved $60 \%$ in the FCI posttest, which according to the creators of FCI is the "entry threshold" for understanding Newtonian mechanics ${ }^{11}$. Students below this threshold are likely to have difficulty solving mechanics problems in the future. We will continue to work with the Physics department to create conditions that support more student learning of physics.

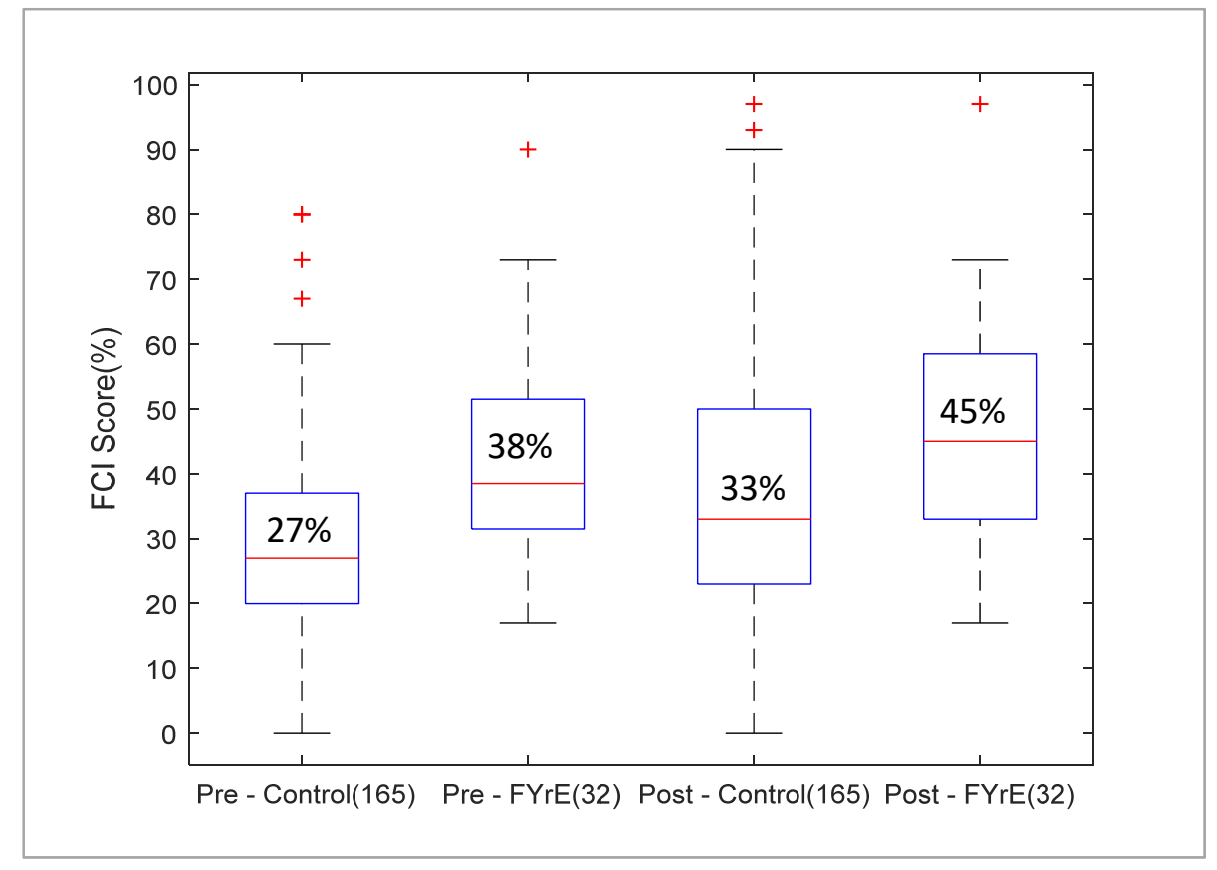

Figure 6. Results of FCI pretest and posttest for Spring 2018 FYrE and non-FYrE groups.

\footnotetext{
${ }^{11}$ Hestenes, David \& Wells, Malcolm \& Swackhamer, Gregg. (1992). Force Concept Inventory. The Physics Teacher. 30. 141-158. 10.1119/1.2343497.
} 
The fact that FYrE cohorts were often unintentionally assigned to instructors with high DFW rates may explain why the overall latitudinal results are not as good as expected, especially considering the qualitative results to be discussed later in this paper. Nevertheless, there is some evidence that the program is having a positive impact on student academic performance.

\section{$\underline{\text { FYRE Qualitative Results }}$}

Since Fall 2015, we have conducted a variety of surveys, in addition to individual and focus group interviews with FYrE students, SI leaders, and faculty and staff involved in the FYRE experiment. The preponderance of these results have shown that FYrE has a tremendous influence on students' reported study habits, social cohesion, usage of university resources, and access to faculty and staff.

Findings from focus groups, surveys and interviews with past FYrE students reveal that FYrE students feel part of a community. A participant in one of three focus groups conducted in November 2018 with 24 first-year students in the FYrE 2018 cohort explained: "FYrE gives you a branched support system. You have FYrE faculty on one side supporting you, and your peers on the other side. Upper class students can also support you. When you leave FYrE, you are ready to move on." In the focus groups, students spoke of how they support each other and the benefits they see themselves deriving from being part of a team. "We organized ourselves into an online chat room where we can help each other any time. If somebody didn't understand the lecture others may have examples." Focus group participants also noted that they learn from experiencing how other students approach problem-solving and several agreed that the lessons they are gaining working with their peers, including students with engineering majors different from their own, will help them in the future when they work in teams with other engineers. When asked how FYrE has influenced their thinking about what it means to be an engineering student, focus group participants agreed that FYrE had contributed to rewrite their expectations. One student explained: "High school was very simple. You do homework so you can get into college. Here it is much more complex. You have to be multi-focused. Think... what do I need to do now to get a good engineering job. I need internships, connections. I need to be networking."

The students were queried about how FYrE contributes to transforming their high school mindset to a more sophisticated outlook that recognizes the value of office hours and getting to know professors, internships, clubs, and networking. One major factor that opens the mindset of the incoming FYrE students is their interaction with upper-division students through Supplemental Instruction (SI). In focus groups and surveys, students point repeatedly to the SI leaders as a powerful and credible source of support, wisdom and guidance. "SI leaders are closer to us in age, they have also literally been through what we are going through right now. They provide inside information." In interviews conducted with seven SI leaders, one participant explained: "We teach students to ask a question in a way that sets them up to answer it themselves." SI leaders also spoke of how they encourage students to go to office hours, join clubs, network, and think ahead about the letter they will need from a professor when they apply for an internship. Even some of these assignments, FYrE students approach as a community. A FYrE instructor explained in an interview: "They [FYrE students] would come to office hours as a group of 4 or 5. This doesn't happen in other classes." And the team approach extends into the classroom and lab. A FYrE lab instructor noted: "In lab activities, there would be more communication among 
the groups [of FYrE students]. Typically students ask me questions. The FYrE students would ask their peers more. This left me with more time to move around."

A key question is whether the benefits derived from being part of the FYrE community lasts beyond the FYrE intervention period. An initial exploration of this question that included interviews with SI Leaders and FYrE students one year out suggests that the team spirit, mindset and connections persist, including for those who fail Calculus and thereby are no longer part of FYrE. One student, now a sophomore, recalled in an interview: "FYrE helped me meet everybody. I made friends and networked with everybody from the advisors to the upper division students and the professors. I know most people in the Engineering department now. I can go up to them and ask questions." One of his peers who similarly looked back at FYrE a year out commented: "Although we [the FYrE17 Cohort] no longer have the same schedule, we still meet up. We hang out in the library together like last year and sometimes go over math and physics problems together."

\section{Conclusions and Future Work}

Our preliminary results indicate promising practices and preliminary success of the FYrE program. The First-Year Experience (FYrE) program was introduced in the College in the Fall of 2015 to provide academic and non-academic support to freshmen in their first year of college. Although the program is open to all calculus-ready freshmen, the program is driven by the needs of first-generation college students. Qualitative results suggest that students develop a sense of community since they take all first-year courses with the same cohort. That alone may have assisted them in creating a peer-support system and study groups. The sense of community, mindset and connections seems to persist beyond the students' first year in engineering and computer science. Additionally, the students report development of a more sophisticated view of college and an understanding of how to benefit from support and available learning opportunities. This student perception will be empirically measured in future years by a survey of students' college social capital to determine if these changes in mindset impact their academic performance and persistence in STEM into and beyond their freshman year in college. Both participating students and their faculty report great value of the Supplemental Instruction (SI) student leaders in the program as a credible source of academic support and mentorship. Quantitative results brought up wide variability in course pass rates, which led to discussions with other departments outside the college. Consequently, we have initiated the development of a community of faculty with similar mindset towards teaching. We have begun to investigate how to provide appropriate professional development for instructors (almost exclusively lecturers) teaching fundamental math and science to engineering students so that pedagogical approaches are more in line with the needs of first generation, low income college students. When we started the FYrE program, we understood that it would take multiple academic years to fully develop a large-scale program that provides the support needed by many of our students, especially due to the inertial resistance and politics of academia. In future years, we intend to track the entering students to degree matriculation and determine if students participating in the FYrE program demonstrate greater persistence in engineering and computer science majors and if their academic performance is positively impacted across years in college by their first year experience. Thus far through a data-driven assessment process, we have been able to slowly change the mindsets of people involved in the academic program and have developed a strong community that is determined to invest in the support programs our students need and deserve. 
We believe that there is much work left to do, however we are also excited and optimistic about the progress that we have made.

\section{$\underline{\text { Acknowledgements }}$}

This work is currently supported by the National Science Foundation (DUE-1727054). Any opinions, findings, and conclusions or recommendations expressed in this material are those of the authors and do not necessarily reflect the views of the National Science Foundation. The work was initiated through a STEM Collaborative grant awarded by the Leona M. and Harry B. Helmsley Charitable Trust. Development of the freshman engineering course was also supported by the Boeing Company and by a STEM grant from the Office of Naval Research (Contract Number N00014-15-1-2434). The authors are also grateful for support from the Provost's Office for the FYrE program, and to Professor Monika Kress of the Department of Physics and Astronomy at San José State University, who provided insight on her pre-physics course development. Finally, the contributions of the entire FYrE faculty and staff team, notably Debbie Won, Mark Tufenkjian, Zilong Ye, Sharri Kornblum, Ni Li, Frances Hidalgo, Evelyn Crosby, and Gerardo Lopez are gratefully acknowledged. 